\title{
A Thermodynamic Formulation of Economics
}

Juergen Mimkes

The thermodynamic formulation of economics is based on the laws of calculus. Differential forms in two dimensions are generally not exact forms $(\delta Q)$, the integral from $(A)$ to $(B)$ is not always the same as the integral from $(B)$ to $(A)$. It is possible to invest little in one way and gain a lot on the way back, and to do this periodically. This is the mechanism of energy production in heat pumps, of economic production in companies and of growth in economies. Not exact forms may be turned into exact forms $(d S)$ by an integrating factor $T, d S=\delta Q / T$. The new function $(S)$ is called entropy and is related to the probability $(P)$ as $S=\ln P$. In economics the function $(S)$ is called production function. The factor $(T)$ is a market index or the standard of living, GNP/capita, of countries. The dynamics of economic growth is based on the Carnot process, which is driven by external resources. Economic growth and capital generation - like heat pumps and electric generators - depend on natural resources like oil. GNP and oil consumption run parallel for all countries. Markets and motors, economic and thermodynamics processes are all based on the same laws of calculus and statistics.

\section{1}

\section{Introduction}

In the last ten years new interdisciplinary approaches to economics and social science have been developed by natural scientists. The problems of economic growth, distribution of wealth, and unemployment require a new understanding of markets and society. The dynamics of social systems has been introduced by W. Weidlich (1972) [17] and H. E. Stanley (1992) [15] has coined the term econophysics. A thermodynamic approach to socio-economics has been favored by D. K. Foley (1994) [4], J. Mimkes (1995) [10] and Drăgulescu and V. M. Yakovenko (2001) [3]. Financial markets have been discussed by M. Levy et al. (2000) [8], S. Solomon and Richmond (2001) [14], Y. Aruka (2001) [1] and many others. Many conferences have been held to enhance the communication between natural and socio-economic sciences with topics like

Econophysics and Sociophysics: Trends and Perspectives.

Bikas K. Chakrabarti, Anirban Chakraborti, Arnab Chatterjee (Eds.)

Copyright (c) 2006 WILEY-VCH Verlag GmbH \& Co. KGaA, Weinheim ISBN: 3-527-40670-0 
$2 \mid 1$ A Thermodynamic Formulation of Economics

econophysics, complexity in economics and socio-economic agent systems. In the first chapter, the mechanism of economic production is discussed on the basis of calculus and statistics. The two mathematical fields will be applied to economics in a similar way to thermodynamics, this is the thermodynamic formulation of economics.

1.2

\section{Differential Forms}

1.2.1

\section{Exact Differential Forms}

The total differential of a function $f(x, y)$ is given by (see, e.g., W. Kaplan [6])

$$
d f=(\partial f / \partial x) d x+(\partial f / \partial y) d y
$$

The second (mixed) derivative of the function $f(x, y)$ is symmetric in $x$ and $y$,

$$
\frac{\partial^{2} f}{\partial x \partial y}=\frac{\partial^{2} f}{\partial y \partial x}
$$

In the same way every differential form

$$
d f=a(x, y) d x+b(x, y) d y
$$

is called total or exact, if the second derivatives

$$
\partial a(x, y) / \partial y=\partial b(x, y) / \partial x
$$

are equal. Exact differential forms are marked by the " $d$ " in $d f$. The function $f(x, y)$ exists and may be determined by a line integral,

$$
\int_{A}^{B} d f=\int_{A}^{B}\left(\frac{\partial f}{\partial x} d x+\frac{\partial f}{\partial y} d y\right)=f(B)-f(A)
$$

The closed integral of an exact differential form is zero: The closed integral may be split into two integrals from $A$ to $B$ on path (1) and back from $B$ to $A$ on path (2). Reversing the limits of the second integral changes the sign of the second integral. Since both integrals depend on the limits $A$ and $B$ only, the closed integral of an exact differential is zero:

$$
\oint d f=\int_{A}^{B} d f_{(1)}+\int_{B}^{A} d f_{(2)}=\int_{A}^{B} d f_{(2)}-\int_{A}^{B} d f_{(2)}=0
$$




\section{Example:}

$$
\begin{aligned}
f(x, y) & =x^{3} y^{5} \\
d f & =\left(3 x^{2} y^{5}\right) d x+\left(5 x^{3} y^{4}\right) d y \\
\frac{\partial^{2} f}{\partial x \partial y} & =3 \cdot 5 \cdot x^{2} y^{4}=\frac{\partial^{2} f}{\partial y \partial x} \\
\oint d f & =0
\end{aligned}
$$

\section{2 .2}

\section{Not Exact Differential Forms}

In one dimension all differential forms are exact. A two-dimensional differential form $\delta g$

$$
\delta g=a(x, y) d x+b(x, y) d y
$$

is not always an exact differential form. The second derivatives are generally not equal,

$$
\partial a(x, y) / \partial y \neq \partial b(x, y) / \partial x
$$

These differential forms are called not exact and are marked by the " $\delta$ " in $\delta g$. A function $g(x, y)$ does not exists in general and may not be determined by a line integral, because the line integral of not exact differential forms depends on the integral limits $A$ and $B$ and on the path of integration. Any different path of integration will lead to a new function $g(x, y)$. A closed integral from $A$ to $B$ along path (1) and back from $B$ to $A$ along path (2) will not be zero,

$$
\oint \delta g=\int_{A}^{B} \delta g_{(1)}-\int_{A}^{B} \delta g_{(2)} \neq 0
$$

Example: We may construct a non exact differential form by dividing $d f(1.7)$ by $y$ :

$$
\begin{aligned}
& \delta g=d f(x, y) / y=\left(3 x^{2} y^{4}\right) d x+\left(5 x^{3} y^{3}\right) d y \\
& 12 x^{2} y^{3}=\partial a(x, y) / \partial y \neq \partial b(x, y) / \partial x=15 x^{2} y^{3}
\end{aligned}
$$

In Fig. 1.1. the closed integral of $\delta g$ is calculated for path (1) from point $A=$ $(1 ; 1)$ along the line $(y=1)$ to $B=(2 ; 1)$ and then along the line $(x=2)$ to point $C=(2 ; 2)$.

$$
\begin{aligned}
\int_{1 ; 1}^{2 ; 2} \delta g_{1} & =\int_{1}^{2}\left(3 x^{2}(y=1)^{4} d x+\int_{1}^{2} 5(x=2)^{3} y^{3} d y\right. \\
& =\left(2^{3}-1^{3}\right)+5 \cdot 2^{3}\left(2^{4}-1^{4}\right) / 4=157
\end{aligned}
$$


The second integral of $\delta g$ is calculated for path (2) from point $A=(1 ; 1)$ along the line $(x=1)$ to point $D=(1 ; 2)$ and then along the line $(y=2)$ to point $C=(2 ; 2)$ :

$$
\begin{aligned}
\int_{1 ; 1}^{2 ; 2} \delta g_{2} & =\int_{1}^{2}\left(3 x^{2}(y=2)^{4} d x+\int_{1}^{2} 5(x=1)^{3} y^{3} d y\right. \\
& =2^{4}\left(2^{3}-1^{3}\right)+5 \cdot 1^{3}\left(2^{4}-1^{4}\right) / 4=130,75
\end{aligned}
$$

The closed line integral along path $(1)$ from $A=(1 ; 1)$ via $B=(2 ; 1)$ to $C=$ $(2 ; 2)$ and back along path (2) from $C$ via $D=(1 ; 2)$ to $A=(1 ; 1)$ - see Fig. 1.1 - is

$$
\oint \delta g=\int_{A}^{B} \delta g_{(1)}+\int_{B}^{A} \delta g_{(2)}=157-130,75=26,25 \neq 0
$$

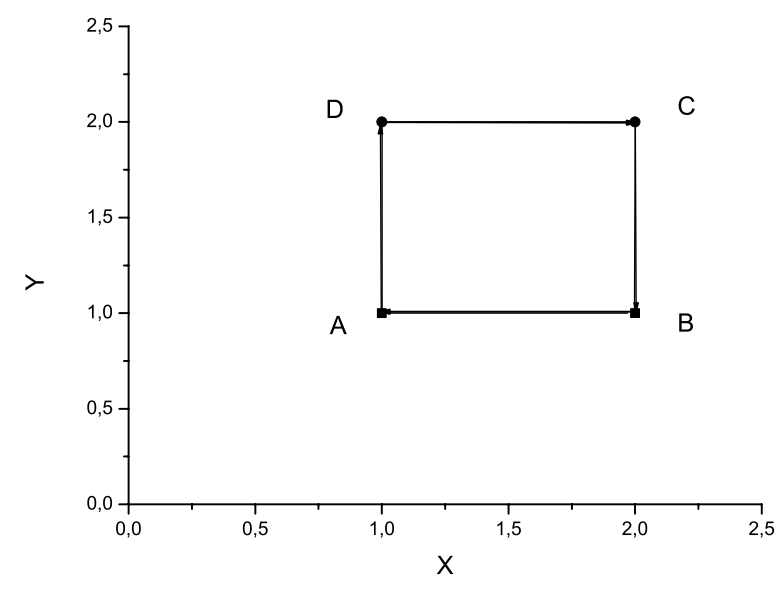

Fig. 1.1 The closed line integral along path $(1)$ from $A=(1 ; 1)$ via $B=(1 ; 2)$ to $C=(2 ; 2)$ and back along path $(2)$ from $C$ via $D=(2 ; 1)$ to $A$ is not zero!

\section{2 .3}

\section{The Integrating Factor}

A two-dimensional differential form $\delta g$ may be made exact by an integrating factor $1 / T$ :

$$
d f=\delta g / T=[a(x, y) d x+b(x, y) d y] / T
$$


(Sometimes the integrating factor is also called $\lambda$, but with respect to thermodynamics the factor $1 / T$ will be used here.) In two dimensions this factor always exists.

Example: The non total differential form $\delta g$ (1.11) has been obtained by dividing the exact form $d f(1.7)$ by " $y$ ". Accordingly, $y=1 / T$ will be the integrating factor of $\delta g$.

\subsection{4}

\section{The First and Second Law of Differential Forms}

The results above may be stated in two laws for differential forms:

The first law of differential forms:

Two-dimensional differential forms $\delta g$ will generally not be exact.

The second law of differential forms:

A not exact differential form may be made exact by an integrating factor $1 / T$.

\section{2 .5}

\section{Not Exact Differential Forms in Thermodynamics and Economics}

Why are differential forms and calculus of not exact forms so important for thermodynamic and economics?

1. Thermodynamics. Heat is a function of at least two variables, temperature and pressure. According to the first law of differential forms, heat $(\delta Q)$ will be a non exact differential form. The value of the integral from $(A)$ to $(B)$ will not be the same as from $(B)$ to $(A)$. This makes the first law of differential forms so important in the application to periodic machines: it is possible to invest little heat in one way and gain a lot of heat on the way back and to do this periodically.

Heat pumps. A heat pump or generator may periodically invest $1 \mathrm{kWh}$ of energy in one way and gain $5 \mathrm{kWh}$ on the way back!

The second law makes it possible to calculate a complicated technical process of not exact differential forms by a simple function. This makes thermodynamics so important for theory and application (see, e.g. R. Fowler and Guggenheim (1960) [5]).

2. Economics. Economic growth is a function of at least two variables, labour and capital. According to the first law of differential forms profit $(\delta Q)$ will not be an exact differential form. The value of the integral from $(A)$ to $(B)$ will not be the same as from $(B)$ to $(A)$. This makes the first law of differential forms so attractive in the application to periodic production: it is possible to invest little capital in one way and gain a lot of capital on the way back and to do this periodically: 
6 1 A Thermodynamic Formulation of Economics

Banks. A bank may periodically invest $4 \%$ of interest in savings and collect $10 \%$ interest from investors.

Companies. A company may periodically pay as little as possible to workers and collect periodically as much as possible from customers.

The second law makes it possible to calculate a complicated technical process of not exact differential forms by a simple function. This makes the thermodynamic formulation of economics so important for theory and application in economics and business.

1.3

\section{The First Law of Economics}

\subsection{1}

\section{The First Law: Capital Balance of Production}

Economic production in farms, automobile plants, medical offices or banks is achieved by hard work, but the output will be different for each type of production. The output depends on each specific production process, or in mathematical terms, on the path of integration. Production may be modeled by calculus of not exact differential forms,

$$
-\oint \delta W=\oint \delta Q
$$

The surplus $(Q)$ is a result of work input $(-W)$. The cyclic process of economic production Eq. (1.13) may be split into two parts, the integral from $A$ to $B$ and back from $B$ to $A$,

$$
-\oint \delta W=\oint \delta Q=\int_{A}^{B} \delta Q_{(1)}-\int_{A}^{B} \delta Q_{(2)}=Y-C=\Delta Q
$$

The economic process consists of output $(Y)$ and input $(C)$, the difference is the surplus $\Delta Q$. (The letter $S$ for surplus in standard economics has been replaced by $\Delta Q$.) Income $(Y)$ and costs or consumption $(C)$ are both part of the same production cycle, and depend on the specific production and consumption processes. Surplus and economic growth cannot be calculated in advance (ex ante), unless the whole process is entirely known.

Equation (1.14) may be written in differential forms. If two not exact differentials $(-\delta W)$ and $(\delta Q)$ are equal along the same path of integration, they may differ only by a total differential form $(d E)$, which will always vanish for closed integrals,

$$
\delta Q=d E-\delta W
$$

This is the first law of economics in differential form. It is a capital balance of production. The surplus $(\delta Q)$ will increase the capital $(d E)$ and requires 
the input of work $(-\delta W)$. The main feature of this first law of economics is the fact that the capital balance of production cannot be expressed by definite functions. The capital balance can only be given by not exact differential forms! Eq. (1.13) will be discussed in more detail below.

\subsection{2}

\section{Work $(W)$}

Work $(W)$ is the effort and know-how which we invest in our job. The function $(W)$ does not exist as a general function, it always depends on the path of integration, the production process. Accordingly, $(W)$ cannot be calculated "ex ante". Work is not equivalent to labor, which defines the number and kind of people in the production process. Work is equivalent to the production process. The dimension of $(W)$ is capital, the same as capital $(E)$ and surplus $(Q)$. In thermodynamics the function $(W)$ refers to work of machines. In economics the function $(W)$ may refer to people as well as to machines! The thermodynamic formulation of economics reveals a problem of modern production namely that people and machines work according to the same laws, Eq. (1.13). If people do not work efficiently, they may be replaced by machines: in construction labor will be taken over by cranes and motors, in offices work may be done by computers.

\subsection{3}

\section{Surplus $(\Delta Q)$}

The surplus $(\Delta Q)$ is the result of work $(W)$, Eq. (1.13), and again cannot be calculated "ex ante", as $(\delta Q)$ is a not exact differential form. The integral depends on the path of integration, the surplus depends on the production process. The thermodynamic formulation of economics makes it possible to compare economic production to work in thermodynamics.

Heat pumps. A heat pump is close to the energy reservoir of a river or garden. A heat pump or generator may periodically invest $1 \mathrm{kWh}$ of energy one way and gain $5 \mathrm{kWh}$ on the way back! The heat output $(Q)$ is larger than the work input $(W)$. Where does the heat come from?

In each cycle the heat $(\Delta Q)$ is pumped from the environment, the garden or river, which will be cooled down when the heat pump is operating. In gardens or rivers the energy loss will be filled up from the reservoir of the environment.

Banks. A bank is close to the capital reservoir of savers. A bank may periodically invest $4 \%$ of interest in savings and collect $10 \%$ interest from investors. The output $(Q)$ is larger than the input $(W)$ ! Where does the surplus come from?

For banks the surplus capital for each cycle is taken from the growth of the saving community. It is not only the first member of an economic chain which 
8 1 A Thermodynamic Formulation of Economics

exploits nature and the environment, but all other members of an economic chain do the same in each production cycle. This mechanism of economic growth will be discussed in more detail in the Carnot process, below.

\subsection{4}

\section{Capital $(E)$}

The capital $(E)$ is the basis of economic production $(W)$. The farm is the capital of the farmer, the production plant is the capital of a company, the investment the capital of investors.

Without labour $(W)$ capital cannot grow. Only by an input of work may the capital increase. Of course, capital may also decrease by mismanagement or failures. But every economic system has to produce positive surplus in order to survive. After each production cycle the surplus $(\Delta Q)$ has to be in a reasonable relationship to the invested capital $(E)$. The relation

$$
r=-\oint \delta W / E=\oint \delta Q / E=\Delta Q / E
$$

is called the efficiency of the production cycle $(\delta \mathrm{W})$. The ratio " $r$ " is called the interest rate and is given in percent. The efficiency or interest rate measures the success of a production cycle $(\delta W)$ and determines, whether people or machines will be employed in a specific production process.

\section{4}

\section{The Second Law of Economics}

\subsection{1}

The Second Law: Existence of a System Function (S)

The not exact differential form $\delta Q$ may be changed into an exact differential form $d S$ by an integrating factor $T$. This is called the second law:

$$
d S=\frac{1}{T} \delta Q
$$

Equation (1.17), is a law for the existence of a system function $(S)$, which is called entropy in physics and information science. Economists usually call this function the production or utility function. $1 / T$ is the integrating factor.

\subsection{2}

\section{The Integrating Factor $(T)$}

$1 / T$ is the integrating factor of the capital balance (1.13). $T$ is proportional to the mean capital ( $E)$ of $N$ agents of the specific economic system,

$$
E=c N T
$$


$c$ is a proportional factor. $T$ may be regarded as an "economic temperature". In a market of $N$ commodities, $T$ is proportional to the mean price level. In a society of $N$ households $T$ is proportional to the mean capital per household, or standard of living. In countries, $T$ is proportional to the GDP per capita. $T$ is introduced by the second law as the main variable in all economic functions.

\section{4 .3}

\section{Entropy and Production Function $(S)$}

Inserting Eq. (1.17) into (1.13) we find

$$
-\oint \delta W=\oint T d S
$$

The entropy or production function $(S)$ is closely related to the work function $(W)$. But in contrast to $(W)$ the function $(S)$ is independent of the production process, it has the dimension of a (production) number and may be calculated "ex ante". The functions $(W)$ and $(S)$ represent mechanism and calculation in all economic processes:

The work function $(W)$. The work function $(W)$ is defined by the production process and may be different for each process. This makes it possible to invest little in one part of the process and gain much in another part of the production process in order to obtain a surplus.

The production function $(S)$. The entropy or production function $(S)$ depends on the system and makes it possible to calculate the economic process "ex ante".

\subsection{4}

\section{Pressure and Personal Freedom}

In Eq. (1.17) the non exact form $\delta Q$ has been expressed by $d S: \delta Q=T d S$. In the same way the non exact form of production $(\delta W)$ may be expressed by the exact differential form $d V$,

$$
\delta W=-p d V
$$

The parameter $p$ may be called the pressure, $V$ may be regarded as space or personal freedom, which may be reduced due to the external economics or social pressure.

\section{4 .5}

\section{The Exact Differential $(d S(T, V))$}

According to Eq. (1.17) and (1.20) the entropy $(d S)$ may be written as an exact differential form of $T$ and $V$ :

$$
d S(T, V)=\frac{\partial S}{\partial T} d T+\frac{\partial S}{\partial V} d V=\frac{1}{T}(d E(T, V)+p(T, V) d V)
$$


10 1 A Thermodynamic Formulation of Economics

$$
d S(T, V)=\frac{1}{T} \frac{\partial E}{\partial T} d T+\frac{1}{T}\left(\frac{\partial E}{\partial V}+p\right) d V
$$

The exact differential $d S$ may be integrated independent from the path of integration. The production function $S(T, V)$ depends on capital $E(T, V)$ and economic pressure $p(T, V)$. However, other variables, like $S(T, p)$ are also possible, they require additional calculations and will be discussed at a later point.

\subsection{6}

\section{The Maxwell Relation}

The functions $E$ and $p$ cannot be chosen arbitrarily, as the mixed differentials of the exact form $d S$ in Eq. (1.21) have to be equal. This leads to (exercise!)

$$
\frac{\partial p}{\partial T}=\frac{1}{T}\left(\frac{\partial E}{\partial V}+p\right)=\frac{\partial S}{\partial V}
$$

These "Maxwell relations" are general conditions for all model functions $E(T, V), p(T, V)$ and $S(T, V)$.

Equation (1.21) leads to the existence of a function $F(T, V)$,

$$
F(T, V)=E(T, V)-T S(T, V)
$$

(see exercise). F may be called the "effective costs" function, which will be a minimum for stable economic systems. The function $F$ corresponds to the "Helmholtz free energy" function of thermodynamics.

Exercise: The total differential $d F=d(E-T S)=d E-T d S-S d T$ may be transformed by Eqs (1.15), (1.17) and (1.20) into

$$
d F=-p d V-T d S
$$

The mixed second derivative of $d F$ is given by the Maxwell relation Eq. (1.22).

\subsection{7}

\section{Lagrange Function}

Dividing the function $F(T, V)$ in Eq. (1.23) by $(-T)$ we obtain

$$
L(T, V)=S(T, V)-(1 / T) E(T, V) \rightarrow \text { maximum! }
$$

$L$ is the Lagrange function which maximizes the production function $(S)$ under constraints of costs $(E)$ with a Lagrange multiplier $\lambda=(1 / T)$. This is the result of the first and second law. The discussion of the Lagrange function will be continued in Section 1.5.4. 


\section{Statistics}

1.5.1

\section{Combinations}

The distribution of decisions is given by the mathematics of combinations. For two possible decisions - left/right or yes/no - we find the probability $P$

$$
P\left(N_{L} ; N_{R}\right)=\frac{N_{0} !}{N_{L} ! N_{R} !} \cdot \frac{1}{2^{N}}
$$

$N_{L}$ is the number of decisions for the left side and $N_{R}$ the number of decisions for the right side, $N_{L}+N_{R}=N_{0}$. (N! stands for the product 4 ! $=1 \cdot 2 \cdot 3 \cdot 4$ and $0 !=1)$.

\section{5 .2}

\section{Normal Distribution}

For large numbers $N_{0}$ the probability function $P\left(N_{L}, N_{R}\right)$ in Eq. (1.25) leads to a normal distribution,

$$
P(N)=\frac{1}{\sqrt{2 \pi} \sigma} \cdot e^{-\frac{(N-\bar{N})^{2}}{2 \sigma^{2}}}
$$

with $0 \leq N \leq N_{0}, \bar{N}=N_{0} / 2$ and $2 \sigma=\sqrt{N}$. The normal distribution is one of the most important probability functions in the natural, social and economic sciences.

\subsection{3}

\section{Polynomial Distribution}

In many cases we have more than two decisions, e.g., we can choose the color of a car to be black, white, red, blue, etc. For $N_{0}=N_{1}+\ldots+N_{K}$ and $K$ possible equal decisions we obtain

$$
P\left(N_{1} ; \ldots ; N_{K}\right)=\frac{N_{0} !}{N_{1} ! \cdot \ldots \cdot N_{K} !} \cdot \frac{1}{K^{N}}
$$

If the probability of the decisions is not equal, we have to introduce the probability $q_{k}$ of the decision $k$. The sum of all $q_{k}$ will be equal to one, $\Sigma q_{k}=1$ :

$$
P\left(N_{1} ; \ldots ; N_{K}\right)=\frac{N_{0} !}{N_{1} ! \cdot \ldots \cdot N_{K} !} \cdot q_{1}^{N_{1}} \cdot \ldots \cdot q_{K}^{N_{K}}
$$

If we have $N_{0}$ cars with $K$ different colors and each color has the probability $q_{k}$, then $P\left(N_{1} ; \ldots ; N_{K}\right)$ is the probability to find, in a street with $N$ cars, $N_{1}$ cars of color $1, N_{2}$ cars of color 2 and $N_{k}$ cars of color $k$. 


\section{Lagrange Function in Stochastic Systems}

What is the most probable distribution of apples, pears and bananas under given prices $(E)$ ? Or, what is the most probable distribution of $N$ goods in $K$ different price categories?

The probability $(P)$ will always tend to be a maximum. The most probable distribution of $N$ commodities with constraints of price $E$ may be calculated by the Lagrange function $(L)$,

$$
L\left(N_{k}\right)=\ln P\left(N_{k}\right)-(1 / T) \sum N_{k} E_{k} \rightarrow \text { maximum! }
$$

$P\left(N_{k}\right)$ is the probability according to Eq. (1.28), $N_{k}$ is the number of goods, $E_{k}$ the price in price class $(k),(1 / T)$ is the Lagrange multiplier. Equation (1.29) is the Lagrange function Eq. (1.24) of systems that follow the laws of probability.

Example: The Munich beer garden.

1. A Munich beer garden has $N_{1}$ permanent and $N_{2}$ temporary employees. The wages are $E_{1}=15 €$ per hour for the permanent and $E_{2}=7,5 €$ per hour for the temporary staff. The Lagrange function calculates the optimal output per hour under the constraints of wages $E$,

$$
E=N_{1} E_{1}+N_{2} E_{2}=N\left(x_{1} E_{1}+x_{2} E_{2}\right)
$$

where $x_{k}=N_{k} / N$ is the relative number and $N$ the total number of staff. The entropy for two types of employees is given by

$$
S=N \ln N-N_{1} \ln N_{1}-N_{2} \ln N_{2}=-N\left(x_{1} \ln x_{1}+x_{2} \ln x_{2}\right)
$$

The Lagrange function is maximized,

$$
L=N \ln N-N_{1} \ln N_{1}-N_{2} \ln N_{2}-(1 / T)\left(N_{1} E_{1}+N_{2} E_{2}\right)=\max !
$$

At a maximum the derivatives with respect to $N_{1}$ and $N_{2}$ will be zero. The relative numbers of permanent and temporary staff $x_{1}$ and $x_{2}$ follow a Boltzmann distribution. With the given values of $E_{1}$ and $E_{2}$ we obtain

$$
\begin{aligned}
& x_{1}=\exp \left(-E_{1} / T\right)=0.38 \\
& x_{2}=\exp \left(-E_{2} / T\right)=0.62 \\
& T=15.8 \\
& S / N=0.664 \\
& E / N=10.35
\end{aligned}
$$

The relative numbers of permanent and temporary staff $x_{1}$ and $x_{2}$, the Lagrange parameter $T$, the mean output per person $S / N$ and the mean wages per person may be calculated from the wages $E_{1}$ and $E_{2}$ without any further assumptions. 
2. In standard economics the Cobb Douglas production function $U$

$$
U=N_{1}^{\alpha} N_{2}^{1-\alpha}=N x_{1}^{\alpha} x_{2}^{1-\alpha}
$$

is often used in the Lagrange function. In addition to wages $E_{i}$, the employees $x_{i}$ are rated by an additional elasticity parameter $\alpha$. For an arbitrary value $\alpha=0.7$ we obtain

$$
\begin{aligned}
& x_{1}=\alpha /\left[\alpha / E_{1}+(1-\alpha) / E_{2}\right] / E_{1}=0.538 \\
& x_{2}=\alpha /\left[\alpha / E_{1}+(1-\alpha) / E_{2}\right] / E_{2}=0.462 \\
& T=\left(E_{1} / \alpha\right)\left(N_{2} / N_{1}\right)^{1-\alpha}=22.44 \\
& S / N=x_{1}^{\alpha} x_{2}^{1-\alpha}=0.5141 \\
& E / N=\left(E_{1} x_{1}+E_{2} x_{2}\right)=11.54
\end{aligned}
$$

For all values of $\alpha$ the mean output $S / N$ is lower and the mean wage costs $E / N$ are higher compared to the entropy $S=\ln P$. The Cobb Douglas function is obviously not the optimal production function. The entropy and Cobb Douglas function look very similar and differ by a factor of about 1.4, this is shown in Figs 1.2 and 1.3.

\subsection{5}

\section{Boltzmann Distribution}

In Fig. 1.4 we have $N=10$ buyers looking for automobiles. There are now $K=5$ different car models on the market with the attractiveness $q_{k}=1$. The constraint for each model is the price $E_{k}$. As a result we find $N_{k}$ buyers for each car model $k$.

What is the most probable distribution?

The problem is solved by the Lagrange function (1.29). The probability $P\left(N_{k}\right)$ is given by (1.28):

$$
L\left(N_{k}\right)=\ln \left\{N ! /\left(\Pi N_{k} !\right\} \Pi q_{k}^{N k}-(1 / T) \Sigma_{k}\left(N_{k} E_{k}\right)\right\}=\text { maximum! }
$$

For large numbers $N$ the faculty may be replaced by the Stirling formula

$$
N !=N \ln N-N
$$

where $N$ may be replaced by $N=\left(\Sigma N_{k}\right)$. The Lagrange function is now given by

$$
\begin{aligned}
L\left(N_{k}\right)=\left\{\left(\Sigma N_{k}\right) \ln \left(\Sigma N_{k}\right)-\Sigma\left(N_{k} \ln N_{k}\right)+\Sigma\left(N_{k} \ln q_{k}\right)\right. & \\
\left.-(1 / T) \Sigma N_{k} E_{k}\right\} & \rightarrow \text { maximum! }
\end{aligned}
$$




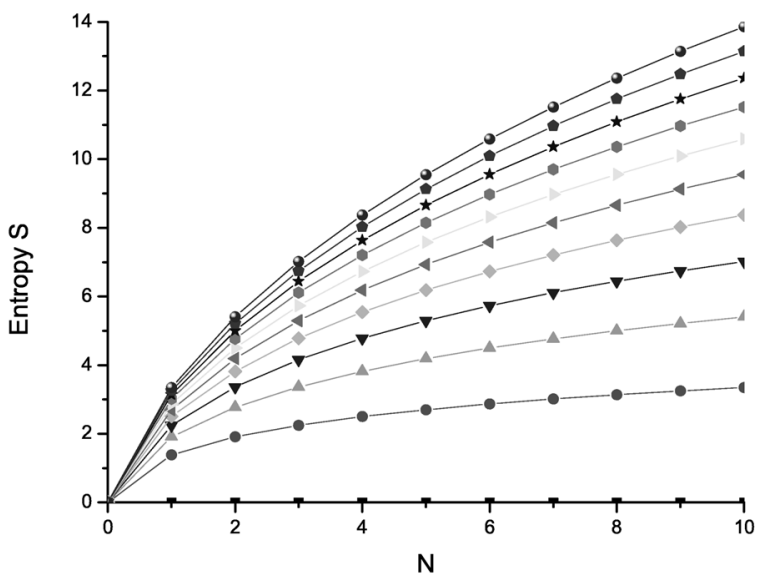

Fig. 1.2 The entropy $S\left(N_{2}\right)=\left(N_{1}+N_{1}\right) \ln \left(N_{1}+N_{1}\right)-N_{1} \ln N_{1}-$ $N_{2} \ln N_{2}$ plotted versus $N_{2}$ in the range from 0 to 10 . The parameter is $N_{1}$ in the range from 0 to 10 .

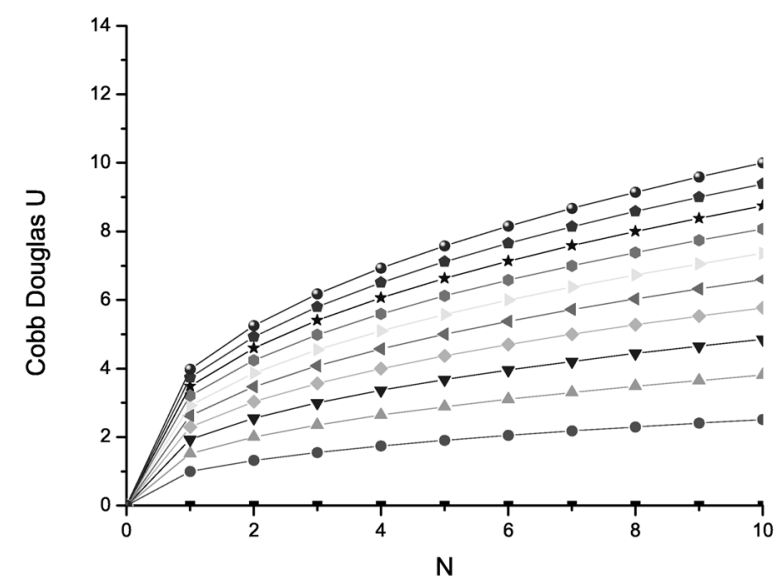

Fig. 1.3 The Cobb Douglas function $U\left(N_{2}\right)=N_{1}^{\alpha} N_{2}^{1-\alpha}$ plotted versus $N_{2}$ in the range from 0 to 10 . The parameter is $N_{1}$ in the range from 0 to 10 . In this range the Cobb Douglas Function is smaller than entropy by a factor of about 1.4 for all values of $\alpha$. The closest match between the functions is obtained for $\alpha=0.4$. 


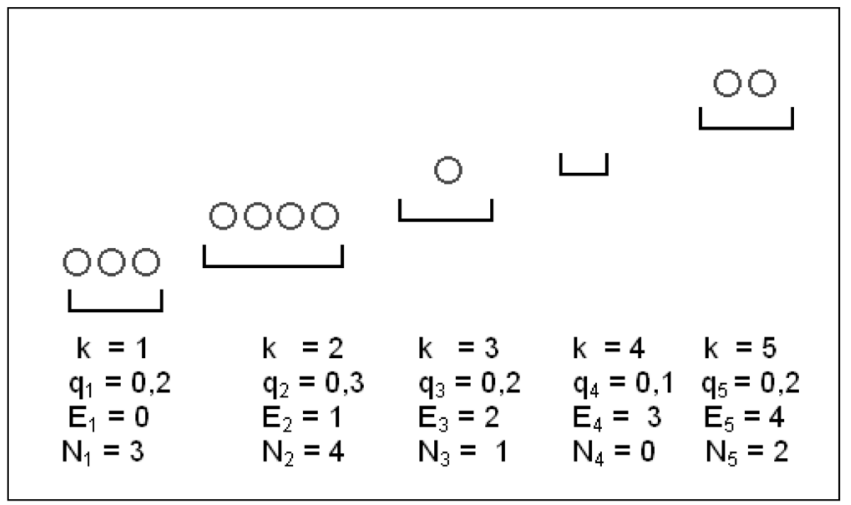

Fig. 1.4 $N=10$ identical buyers are looking for automobiles. There are now $K=5$ different car models on the market with the attractiveness $q_{k}=1$. The constraint for each model is the price $E_{k}$. As a result we find $N_{k}$ buyers for each car model.

At equilibrium the Lagrange function may be differentiated with respect to $N_{k}$

$$
\partial L / \partial N_{k}=\left\{\ln \left(\Sigma N_{k}\right)-\ln N_{k}\right)+\ln q_{k}-E_{k} / T=0
$$

This leads to the distribution of $N_{k}$ different objects as a function of price $E_{k}$,

$$
N_{k} / N=q_{k} \exp \left(-E_{k} / T\right)
$$

The Boltzmann distribution is the most probable distribution of $N$ elements in $K$ categories under constraints $(E)$.

Figure 1.5 shows the distribution of cars sold in the German automobile market in 1998. According to the German tax laws there are four classes of cars, 1.5 liters. 1.8 liters. 2.4 liters and above. The diamond points in Fig. 1.5 are the data of cars sold in Germany in 1998 as given by the automobile industry. The distribution does not yield a Boltzmann distribution, nearly six million units are missing in the lowest category at 1.5 liters or 20000 DEM. However, the number of seven million used cars is reported for Germany in 1998 by the German Automobile Agency in Flensburg. If this number is added to the new cars of 1998 in the lowest price category, a Boltzmann distribution is obtained. Obviously, the complete automobile market is determined by new and used cars!

Figure 1.6 shows traffic violators given by the German Traffic department in Flensburg, in 2000. The number of repeated violators is shown as a function of the fine (in number of points proportional to a fine in $€$ ). The number of violators decreases with a growing fine according to the Boltzmann distribution, Eq. (1.38). The data in Fig. 1.6 exactly follow the calculations. Decisions on 
Automobile market in Germany 1998

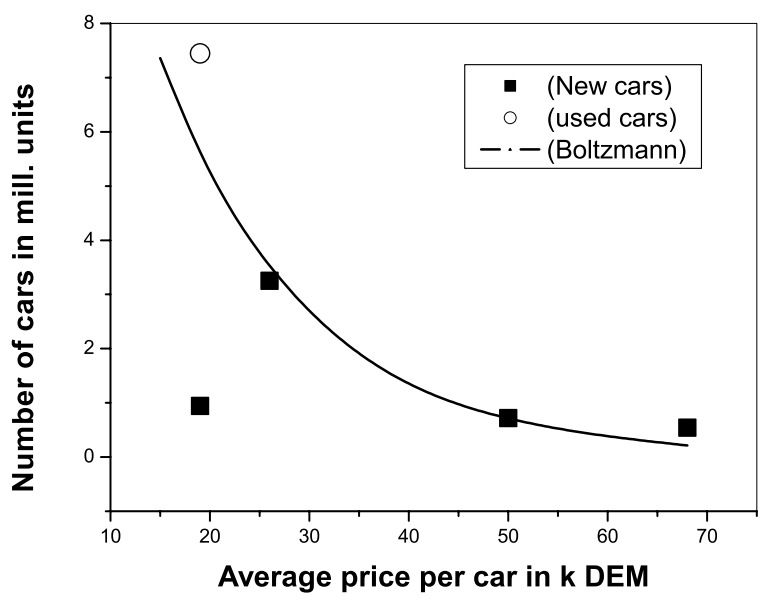

Fig. 1.5 Production of new cars in Germany 1998. According to the German tax classes four types of cars are reported by the industry, 1.5 liters, 1.8 liters, 2.4 liters and above. A Boltzmann distribution,

Eq. (1.38), is obtained only if the number of seven million used cars is added to the lowest price category. The complete automobile market is only given by new and used cars!

buying cars or violating traffic rules depends exponentially on the price $(E)$ in relation to the standard of living $(T)$.

\section{6}

\section{Entropy in Economics}

\subsection{1}

\section{Entropy as a Production Function}

In stochastic systems the production function $(S)$ is given by

$$
S\left(N_{k}\right)=\ln P\left(N_{k}\right) \text {. }
$$

The term entropy $(S)$ is used in mathematics, physics and information science, and has been first introduced to economics by N. Georgescu-Roegen (1974) [7] and more recently by D. K. Foley and J. Mimkes (1994) [4]. In stochastic systems, entropy replaces the Cobb Douglas function of standard economics as a production function. There are several reasons for this replacement.

1. Entropy is a natural system function without additional parameters. The Cobb Douglas function has an arbitrary "elasticity parameter" $\alpha$. 


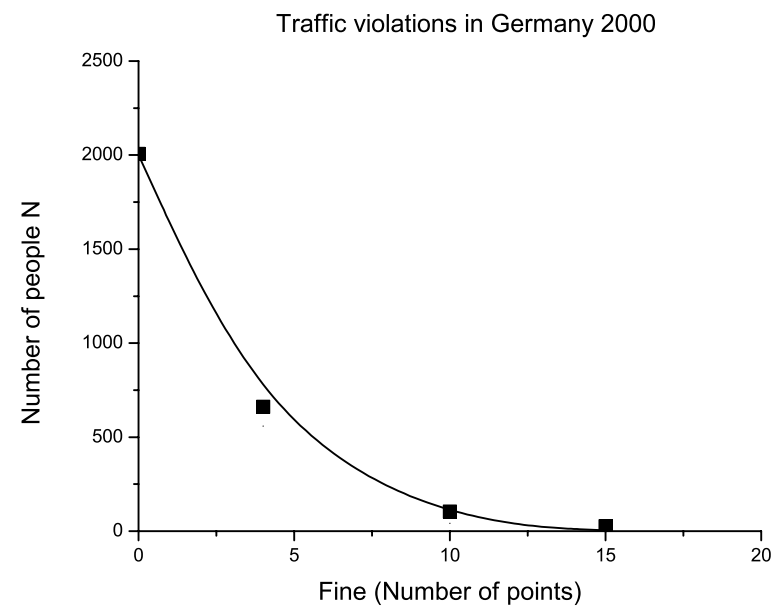

Fig. 1.6 The Boltzmann distribution of repeated traffic violating agents as a function of fine (in points) in Germany 2000. Decisions on violations depend exponentially on the fine $(E)$.

2. The Cobb Douglas function has been found by fitting data, there is no theoretical foundation for this function. The similarity between the functions in Figs 1.2 and 1.3 suggests that entropy would fit the data as well.

3. Figure 1.2 and 1.3 indicate that entropy leads to higher values of production and lower values of costs than does the Cobb Douglas function.

4. In the Lagrange principle the value of different groups of labor are characterized by their wages. They do not need an additional characterization by a parameter $\alpha$. The Lagrange function with entropy is a sufficient characterization of labor groups.

5. Entropy has a very great significance in production and trade, entropy characterizes the change in the distribution of commodities and money during the process of production and trade. This will be discussed in the following section.

\section{6 .2}

\section{Entropy of Commodity Distribution}

We will now discuss the significance of entropy in economics in more detail. 
Example: A farmer sells ten apples. Before the transaction the apples are unevenly distributed, the customers have none and the farmer has all the apples, Fig. 1.7.

\section{$\dot{\pi} \dot{\pi} \dot{\pi} \quad \dot{\pi} 00000$ 00000}

Fig. 1.7 Before selling the ten apples are unevenly distributed, the customers have none and the farmer has all the apples.

The probability for the distribution of ten apples to one out of five persons is given by Eq. (1.28):

$$
\begin{aligned}
& P_{1}=10 ! /(0 ! 0 ! 0 ! 0 ! 10 !) / 5^{10}=5^{-10} \\
& S_{1}=-10 \ln 5=-16.094
\end{aligned}
$$

The farmer sells two apples to each customer and keeps two for himself, Fig. 1.8. Probability and entropy are now

$$
\begin{aligned}
& P_{2}=10 ! /(2 ! 2 ! 2 ! 2 ! 2 !) / 5^{10}=0.0116 \\
& S_{2}=\ln (0.0116)=-4.557
\end{aligned}
$$

The entropy of these distributions is negative, since the probability is always $P \leq 1$.

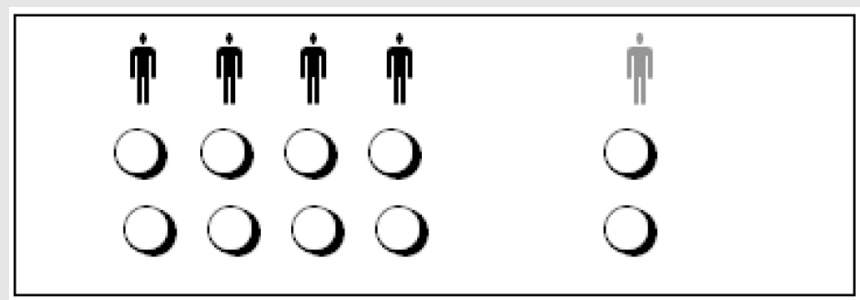

Fig. 1.8 After selling, the apples are evenly distributed, the farmer and each customer has two apples.

In the process of selling, the entropy of apple distribution has changed by

$$
\Delta S=S_{2}-S_{1}=-4.557+16.094=11.437
$$

Selling (distribution) of commodities is equivalent to an increase in entropy. At the end of the sale the distribution of apples has reached equilibrium, all have the same number of apples and the probability and entropy are at a max- 
imum,

$$
S_{2}=\ln P_{2}=\text { maximum! }
$$

The trade of commodities is generally finished when equilibrium has been reached.

\subsection{3}

\section{Entropy of Capital Distribution}

Example: The farmer sells his ten apples for $1 €$ each. Before the transaction the farmer and each of his four customers have two $1 €$ coins in their pockets. The coins are evenly distributed, Fig. 1.9.

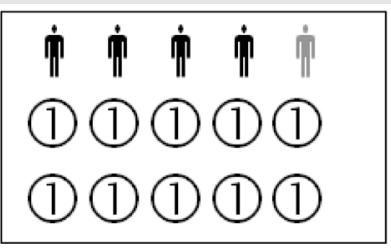

Fig. 1.9 Before selling the ten $1 €$ coins are evenly distributed: all five persons have two $1 €$ coins each in their pocket.

The probability for a distribution of two $1 €$ coins for each of five person is given by

$$
\begin{aligned}
& P_{1}=10 ! /(2 ! 2 ! 2 ! 2 ! 2 !) / 5^{10}=0.0116 \\
& S_{1}=\ln (0.0116)=-4.557
\end{aligned}
$$

The farmer sells two apples to each customer and keeps two for himself, Fig. 1.10. He collects $2 €$ from each customer. The farmer has now $10 €$ in his pocket, the customers have no more $1 €$ coins. The probability and entropy are now

$$
\begin{aligned}
& P_{2}=10 ! /(0 ! 0 ! 0 ! 0 ! 10 !) / 5^{10}=5^{-10} \\
& S_{2}=-10 \ln 5=-16.094
\end{aligned}
$$

\section{市市市

Fig. 1.10 After selling the apples the $1 €$ coins are unevenly distributed: the farmer has all coins and the customers have none. 
In the process of selling, the entropy of the $1 €$ coins distribution has changed by

$$
\Delta S=S_{2}-S_{1}=-16.094+4.557=-11.437
$$

The negative entropy difference indicates that the coins have been collected. The example shows a new aspect of entropy $(S)$. A positive change of entropy in a system of elements (commodities, capital) is equivalent to distributing, while a negative change of entropy corresponds to collecting elements (commodities, capital). In trading the entropies of commodities and capital change in the opposite direction, the absolute entropy difference of commodities and capital is the same.

\section{6 .4}

\section{Entropy of Production}

In the production line of an automobile plant, workers have to assemble parts of a car according to the construction plan. In Fig. 1.11 there are still $N$ different parts, which may be assembled in $P=N$ ! possible ways. Assembling means ordering $N$ parts together in one and only one way according to the construction plan.

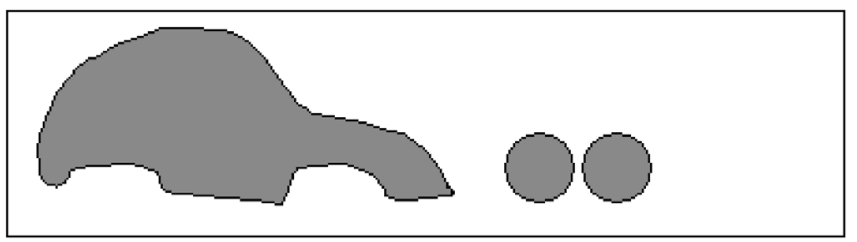

Fig. 1.11 Before assembling $N$ parts of a product there are still $P=N$ ! possibilities. Before production the car is still in disorder.

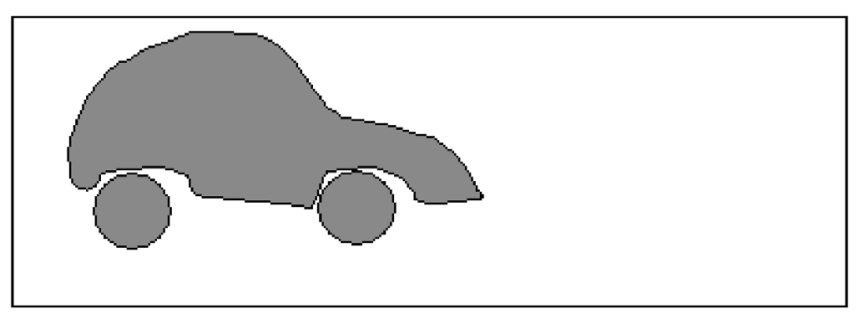

Fig. 1.12 Assembling means ordering $N$ parts in one and only one way according to the construction plan. Production is ordering.

Assembling and ordering according to a plan means entropy reduction, $\Delta S<0$. Work and production are always accompanied by entropy reduc- 
tion. This applies to manual work as well as mental work. A puzzle

$\mathrm{d}+\mathrm{i}+\mathrm{c}+\mathrm{n}+\mathrm{o}+\mathrm{o}+\mathrm{p}+\mathrm{r}+\mathrm{t}+\mathrm{u}=$ production

may be rearranged into a meaningful word. Mental work is ordering many ideas into one meaningful master plan or theory.

1.6 .5

Summary of Entropy

Entropy may have many different aspects, but the main result for entropy may be stated as follows.

$$
\Delta S=S_{2}-S_{1}>0
$$

corresponds to distributing elements like commodities or money and creating disorder.

$$
\Delta S=S_{2}-S_{1}<0
$$

corresponds to collecting elements like commodities or money and creating order.

\section{7}

\section{Mechanism of Production and Trade}

\subsection{1}

\section{The Carnot Process}

The mechanism of production and trade is based on the Carnot process. Equation (1.19) may be integrated along the closed path with $T=$ constant and $S=$ constant in the T-S diagram, Fig. 1.13

$$
-\oint \delta W=\oint \delta Q=\oint T d S=\int_{1}^{2} T_{1} d S+\int_{3}^{4} T_{2} d S=Y-C=\Delta Q
$$

Automobile production is a typical economic process that can be modeled by the Carnot process in Fig. 1.13. The cycle of production starts and ends at point (1).

Example: Carnot cycle of automobile production.

$(1) \rightarrow(2)$ : Automobile production starts at point (1). Workers with a low standard of living $\left(T_{1}\right)$ produce the automobile according to the production plan $(\Delta S)$. The total production costs are given by material $(E)$ and labor: $C=E+T_{1} \Delta S$. The costs could be reduced by building the cars 
according to the same production plan $(\Delta S)$ and same material $(E)$ in a place with low standard of living $\left(T_{1}\right)$.

$(2) \rightarrow(3)$ : Transport of cars from production plant $\left(T_{1}\right)$ to market $\left(T_{2}\right)$.

(3) $\rightarrow$ (4): The automobiles are sold to customers at a market with a high standard of living $\left(T_{2}\right)$. The sales price is given by the material and the market: $Y=E+T_{2} \Delta S$.

$(4) \rightarrow(1)$ : The cycle is closed by recycling the automobile.

The surplus is $\Delta Q=Y-C=\Delta T \Delta S$ and corresponds to the enclosed area in Fig. 1.13.

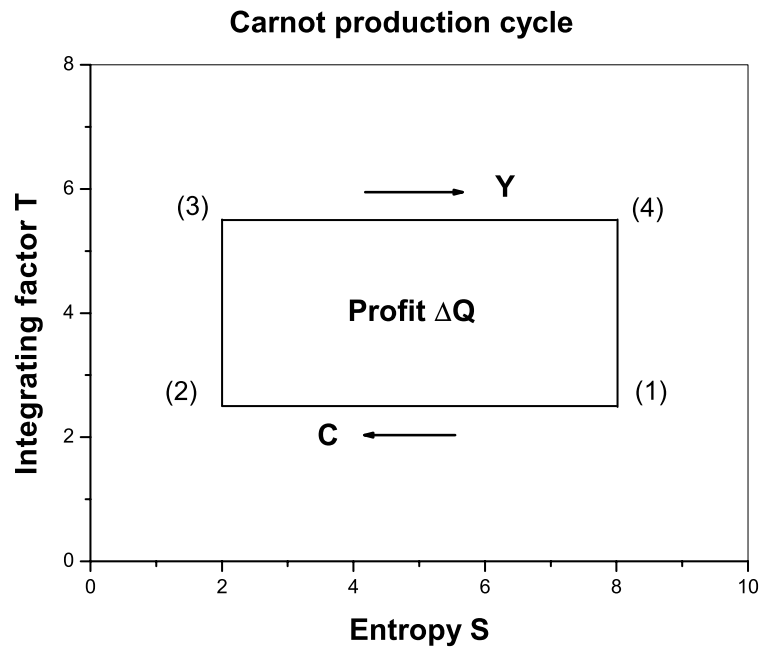

Fig. 1.13 In the Carnot production cycle the flow of goods starts and ends at point (1), (see text).

Example: Carnot cycle of apple farming.

$(1) \rightarrow(2):$ In the fall a farmer collects apples from his trees and stores them in his cellar. The work of collecting apples from the trees leads to a reduction of entropy of apple distribution, $(\Delta S<0)$. The production costs are $C=T_{1} \Delta S . T_{1}$ is the price level of apples in the fall.

$(2) \rightarrow(3)$ : The apples are stored in the cellar without changing the distribution, $S=$ constant.

(3) $\rightarrow(4)$ : In spring the apples are distributed $(\Delta S>0)$ from the farm to the market at the higher price level $\left(T_{2}\right)$ of apples, the total amount of income from the apples is $Y=T_{2} \Delta S$. 
$(4) \rightarrow(1)$ : The apples are sold and there is no change in the distribution of apples until the fall, $S=$ constant. The cycle starts again. The surplus of the apple production cycle is $\Delta Q=Y-C=\Delta T \Delta S$ and corresponds to the enclosed area in Fig. 1.2. The capital flow starts from point (1) and ends at point (1), but capital flow is opposite to the flow of apples, the work $(W)$ and the profit $(Q)$ in Eq. (1.42) have the opposite sign.

$(1) \rightarrow(4)$ : The apple farmer goes to the market. The money in his pocket does not change, $(\Delta S=0)$.

$(4) \rightarrow(3)$ : At the market the apple farmer collects $(\Delta S<0)$ money from the customers.

(3) $\rightarrow(2)$ : The apple farmer returns home without spending the money in his pocket, $(\Delta S=0)$.

$(2) \rightarrow(1)$ : At home the apple farmer distributes $(\Delta S<0)$ part of the money to the apple pickers.

Income $(Y)$, costs $(C)$ and profits $(\Delta Q)$ of labor are determined by

$$
\begin{aligned}
& Y=E+T_{2}\left(S_{4}-S_{3}\right) \\
& C=E+T_{1}\left(S_{2}-S_{1}\right) \\
& \Delta Q=Y-C=\Delta T \Delta S
\end{aligned}
$$

$\Delta Q=Y-C$ is the profit given by the enclosed area of Fig. 13. The materials $(E)$ are the same in production and consumption and do not enter the calculations in a closed cycle. The Carnot process is the basis of all economic processes and will now be discussed in more detail. In economics every company, bank, and every person is a Carnot-like machine. In thermodynamics every motor and energy generator is a Carnot-like machine. In biology every living cell is a Carnot-like machine. The Carnot process is the common mechanism in economics, thermodynamics and biology.

\section{7 .2}

\section{The Origin of Growth and Wealth}

What is the mechanism of economic interaction? If a baker sells bread to his customers, where does the wealth come from? From his work? From his customers?

If buyers and sellers just exchange values, there is no change in wealth and nobody will become richer. Since people make profit and do get rich by economic interactions, agents must take it from somewhere. If one agent takes it from the other agent, there will be no economic transactions, nobody wants to go to a market where he gets robbed. 
2004 GDP per Capita in $\mathrm{k}$ US \$

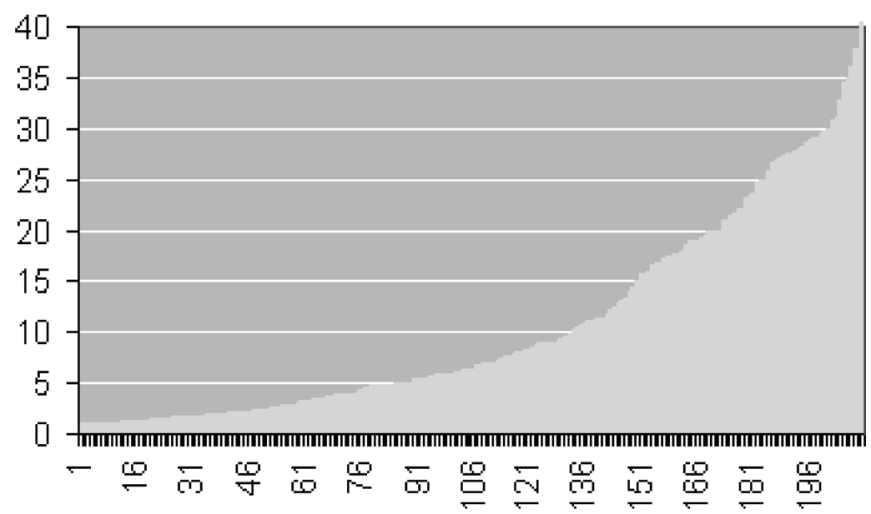

Fig. 1.14 shows the world GDP per capita in US \$ for all countries in 2004. South Asian countries have the lowest and North America the highest GDP per capita.

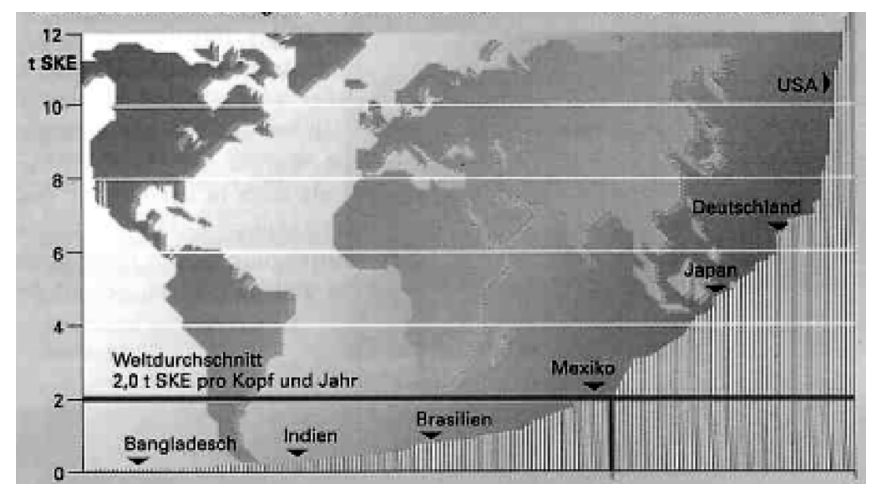

Fig. 1.15 shows the energy consumption in tons of coal in 122 countries in 1991. South Asian countries have the lowest and North America the highest energy consumption. (UN Statistical Yearbook 1991). The shape of the functions in Figs 1.14 and 1.15 are very similar and correspond to nearly the same countries.

The answer is the Carnot process. A heat pump extracts heat from a cold river and heats up a warm house. A bank may extract capital from poor savers and give it to rich investors. Economic interaction of two partners is only possible by exploitation of a third party due to clever manipulation (work). The most common objects of exploitation are natural resources, the environment and common property like water, air, coal and oil. A motor runs on oil, industrial production also runs on oil. Figure 1.14 and 1.15 show the world distribution of wealth (GDP per capita) and the world energy consumption per capita. Both run nearly parallel in all countries. This shows indeed that 
all wealth comes from exploitation. And this is not only true for the first person in the economic chain (like miners and farmers), but for everybody in the economic chain who wants to make a profit.

\subsection{3}

World Trade Mechanism

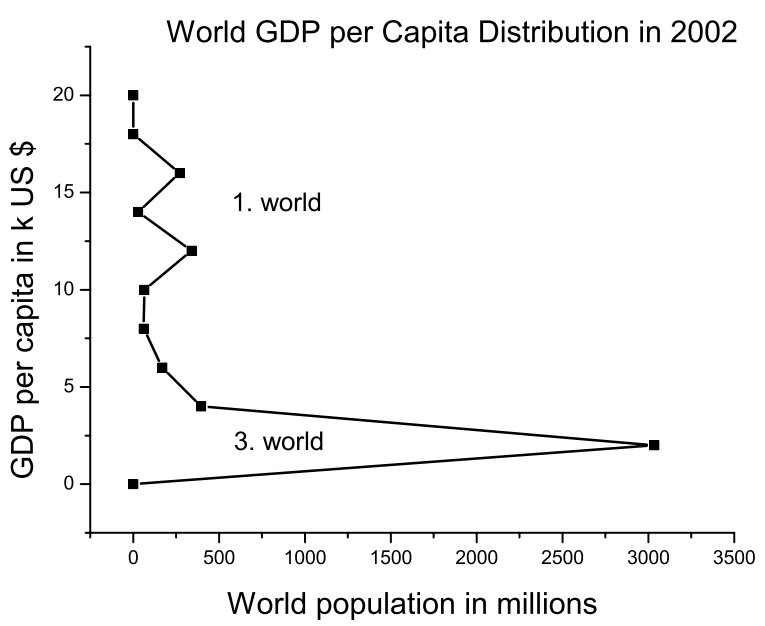

Fig. 1.16 shows the distribution of wealth in the world (CIA World Factbook, USA, 2004). The number of people in different income classes is given by the gross domestic product (GDP) per person. The distribution is clearly divided into two parts. The majority of people (about three billion) in the "third world" live below or close to 2000 US\$ per person.

The minority of about one billion people in the "first world" have an income between 12000 and 15000 US\$ per capita. (The gap at 14000 US $\$$ per capita is an artifact and due to US-EU currency fluctuations.) About two billion people, the "second world" live in between the two extremes.

Machines like motors or heat pumps always require or create two different temperatures $(T)$. Inside the motor it is hot and therefore it needs water or air cooling outside. The heat pump works with a cold river and a warm house, the refrigerator has a cold inside and a warm outside. This difference in temperatures is necessary to make the Carnot process work. The areas of different temperatures have to be separated. If the door of the refrigerator stays open, it will not work, the efficiency is $r=0$.

In all economic systems, work $(W)$ according to the Carnot process always creates two different price or income levels $(T)$. Buying and selling must create two price levels, otherwise there is no reason to do business. But also within a country, production $(W)$ will create poor workers and rich capitalists. 
The two-level system is also observed in the world distribution of wealth. Figure 1.16 shows the GDP distribution of the world and the corresponding number of people. The wealth of nations is clearly divided into two parts. In the "third world" more than three billion people live below or close to a GDP of 2000 US\$ per capita (1995). And in the "first world" about one billion people live between 12000 and 16000 US\$ per capita. (The small dip at 14000 US\$ per capita is more or less artificial and due to fluctuations of the US\$ and EU currencies.)

The Carnot process will stabilize the two different standards of living in the world population. The lower standard will grow with time, but also the difference will grow in order to enhance the efficiency. But the distribution of countries does not have to stay that way for ever. Some countries like China and India will emerge from the bottom and come closer to the top after a decade or two. Some richer countries may stay in the same position or even drop their standard of living. This will be discussed in Section 1.8 on the economic growth of interdependent systems.

\section{7 .4}

\section{Returns}

Profits $\Delta Q=\Delta T \Delta S$ rise with the difference in price and costs $\Delta T$ of the product. The ideal efficiency of production in Eq. (1.16) may now be given by

$$
r=\frac{Y-C}{C}=\frac{T_{2}-T_{1}}{T_{1}}
$$

Example: Dutch Importation of furniture from Indonesia

The GDP per capita in Holland and Indonesia are

$$
\begin{aligned}
& T_{\text {Holland }}=12000 \text { US } \$ \text { per capita and } \\
& T_{\text {Indonesia }}=3000 \text { US } \$ \text { per capita. }
\end{aligned}
$$

Importing local commodities like furniture from Indonesia to Holland leads to an (ideal) efficiency

$$
r=(12000-3000) / 3000=3 \text { or } 300 \% .
$$

Returns are ideally independent of the type of commodity. The efficiency is determined only by the difference in the standard of living $\Delta T$.

The difference in complexity $\Delta S$ does not appear in efficiency calculations. For this reason the entropy function $(S)$ has little importance in macro economics. However, in micro economics, the entropy $(S)$ is linked to the prob- 
ability $(P)$ of the system. This is important for stock markets. A high entropy difference $\Delta S$ indicates a high probability of continuity or security of a share. A company with simple products may quickly be replaced. A company with complex products will last longer. Production $(\Delta W)$ creates a certain area $\Delta T \Delta S$, Fig. 1.13. The area with a large $\Delta T$ and a small $\Delta S$ will be highly efficient but less secure. A large $\Delta S$ and a small $\Delta T$ indicates that this company creates complex products with less efficiency and high security. The area $\Delta T \Delta S$ is determined by the work invested in the product. The shape of the area indicates whether a share is speculative and (perhaps) profitable or secure and less profitable. The optimum for a portfolio of stocks may be a nearly square area $\Delta T \Delta S$ with medium efficiency and medium security.

\section{8}

\section{Dynamics of Production: Economic Growth}

\subsection{1}

Two Interdependent Systems: Industry and Households

The dynamics of economic systems is again based on the Carnot process. So far all equations have been static, as in the thermodynamic formulation of economics the first and second laws do not contain time. But the length of a Carnot cycle is a natural time scale; a day, a month or a year. Economic growth may be handled like a starting motor. Both the inside and outside of the motor will get warmer, depending on how the heat is distributed. In economic systems the profit of each cycle has to be divided between the two sides of the production cycle, $Y$ and $C$. If the lower level $(C)$ gets the share " $p$ " and the higher level $(Y)$ the share $(1-p)$ of the profit $(\Delta Q)$, we obtain:

$$
\begin{aligned}
& d Y_{1}=p \Delta Q d t \\
& d Y_{2}=(1-p) \Delta Q d t \\
& \Delta Q=Y_{2}-Y_{1}
\end{aligned}
$$

The solution of this set of differential equations is:

$$
\begin{aligned}
& Y_{1}(t)=Y_{0}+p\left[Y_{20}-Y_{10}\right][\exp (\alpha t)-1] \\
& Y_{2}(t)=Y_{20}+(1-p)\left[Y_{20}-Y_{10}\right][\exp (\alpha t)-1]
\end{aligned}
$$

with

$$
\alpha=(1-2 p)
$$

According to Eqs (1.47)-(1.52) a rising standard of living $(Y)$ in two interdependent economic systems is determined by the share of the profit " $\mathrm{p}$ " of the group at the lower level $\left(Y_{1}\right)$. The results are shown in Figs 1.17-1.22. 
1. $p=0$; Fig. 1.17. If all profit goes to the richer party $\left(Y_{2}\right)$, the standard of living of group (2) will grow exponentially, the standard of living of the first party stays constant, $\left(Y_{10}\right)$.

2. $p=0.25$; Fig. 1.17. at $25 \%$ of the profit for the poorer party $\left(Y_{1}\right)$ and $75 \%$ for the rich party $\left(Y_{2}\right)$ both parties will grow exponentially. Examples are Japan and Germany after World War II, both economies were depending on the US and were growing exponentially, this is indicated in Fig. 1.18.

3. $p=0.50$; Fig. 1.17. An even split between the two parties leads to a linear growth of both parties. The efficiency of the interaction is reduced with time.

4. $p=0.75$; Fig. 1.19. The growth of both parties is leveling off not much above the initial standard of living. An example is the present USJapanese economic relationship; both economies are close to each other without much economic growth, as shown in Fig. 1.20.

5. $p=1.00$; Fig. 1.19. If all profit goes to the poor side, the standard of living of the poor party soon reaches the constant standard of living of the rich party.

6. $p=1.25$; Fig. 1.21. If more than $100 \%$ of the profit goes to the poor party, $\left(Y_{2}\right)$ will decrease, and $\left(Y_{1}\right)$ will catch up with $\left(Y_{2}\right)$. This has been observed in the relationship of West and East Germany after reunion in 1990, Fig. 1.22.

The data in Figs 1.17-1.22 can only indicate the results of Eqs (1.47)-(1.52), as all countries also have other (less important) interactions with other countries. The results may also be applied to other binary interactive economic systems like industry and households, or in trade. For industries and households the distribution of profit $p$ is determined by the interacting agents of unions and industry, whereas in trade we have buyer and seller. This is now discussed in more detail.

1.8.2

Linear and Exponential Growth $(0<p<0.5)$

Figure 1.17 shows the problem of unions and industry in more detail. Unions tend to ask for high raises in payments, industry urges to invest the profits. Indeed, the fair deal, a split of profits 50:50 between workers and industry (dashed line) in Fig. 1.17 is not the best deal and will only result in linear growth. Workers and industry are much better off in a deal where $90 \%$ of the profits are reinvested (solid lines). Low increase in wages will lead to exponential growth for industry and later for workers as well. But workers 
(as well as their managers) will have to be more patient with pay raises, as in Germany or Japan after World War II, Fig. 1.18.

1.8.3

Trailing Economies: USA and Japan $(0.5<p<1)$

The opposite picture is shown in Fig. 1.19. A high factor $p$ leads to decreasing efficiency, $\left(Y_{1}\right)$ is trailing a decreasing $\left(Y_{2}\right)$. After Japan and Germany have acquired many production plants, the factor $p$ has grown and the efficiency of the exports has started to decrease. In Fig. 1.20 the economic level $\left(Y_{1}\right)$ of Japan is now trailing the slowly decreasing level $\left(Y_{2}\right)$ of the USA.

\section{8 .4}

Converging Economies, West and East Germany $(p>1)$

If the poor side $\left(Y_{1}\right)$ profits very much, $p=p N_{1} /\left(N_{1}+N_{2}\right)>1$, both parties will converge, as shown in Fig. 1.21. This happened during the reunification of West and East Germany, Fig. 1.22. The standard of living in East Germany grew by $100 \%$ within six years, as the standard of living in West Germany was declining. The economic levels $\left(Y_{1}\right)$ and $\left(Y_{2}\right)$ in East and West Germany have nearly converged and differ now, after more than 15 years, by only $20 \%$.

\section{9}

\section{Conclusion}

In the thermodynamic formulation of economics, the laws of markets and societies have been derived from calculus and statistical laws. No further assumptions have been used to derive the laws of economics. The calculated functions are supported by data, which all seem to agree very well. Many arguments indicate that the thermodynamic formulation of economics is a very general approach, which fits the data very well and explains economics and economic growth on the basis of natural science.

However, economic interactions are not only governed by statistical laws. Many economic interactions are restricted by traditional customs, civil laws or by agreements between trading partners. These additional laws will influence the interactions of free economic agents. How will they affect the results above? This will be discussed in more detail in the chapter on "The Thermodynamic Formulation of Social Science". 
Two interdependent economies

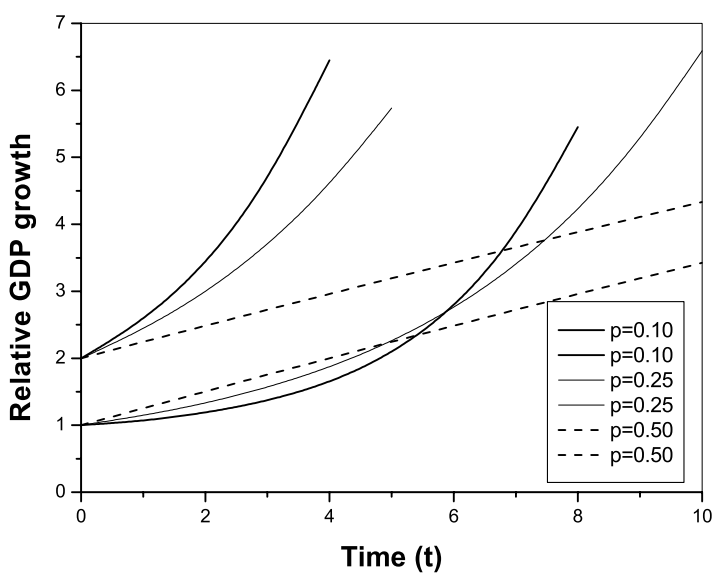

Fig. 1.17 The development of the standard of living of two interdependent economic systems starting at $Y_{1}=1$ and $Y_{2}=2$. The profit for the poor side varies from $p=0.10$ to $p=0.40$. After some time the standard of living of workers $\left(Y_{1}\right)$ will grow with a lower pay raise $p$ !!

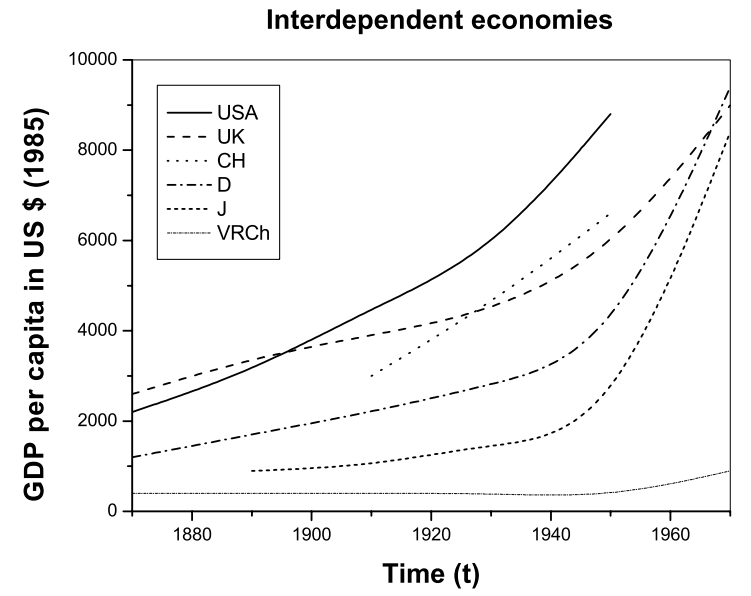

Fig. 1.18 Economic growth of US, UK, Switzerland, Japan, Germany and China between 1870 and 1990. The victorious allies USA and UK have grown exponentially. Japan and Germany only started to grow exponentially after World War II by international trade at low wages. China was excluded and did not take part in economic growth at that stage. 


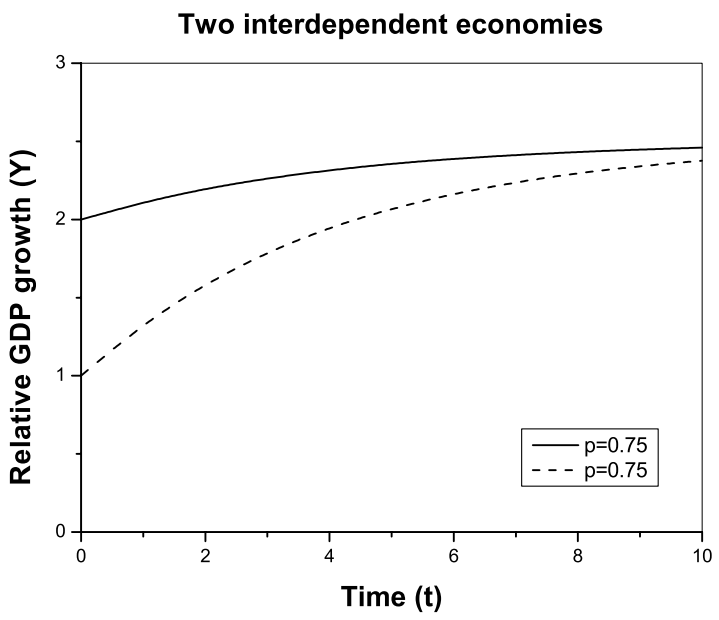

Fig. 1.19 The development of the standard of living of two interdependent economic systems starting at $Y_{1}=1$ and $Y_{2}=2$. At high values of profit for the poor side, $p=0.75$, economic growth is declining with time.

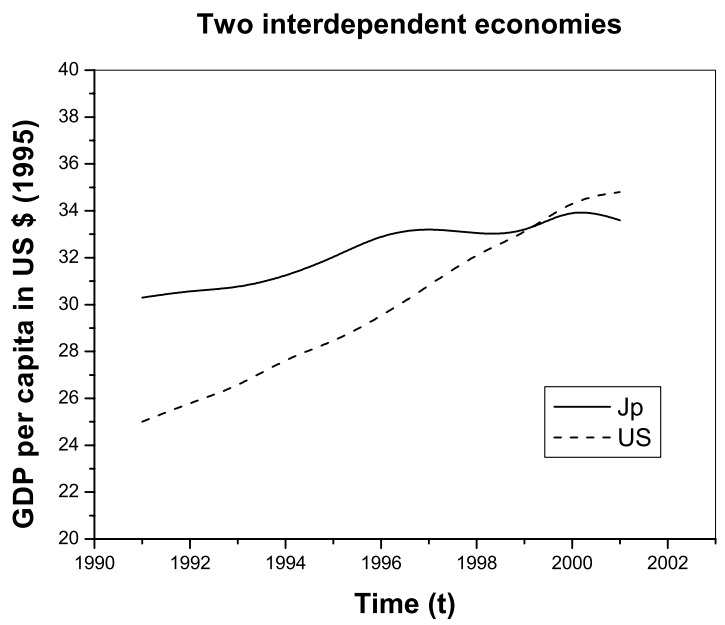

Fig. 1.20 The development of the standard of living (GDP/person) of the USA and Japan in quarters between 1980 and 2000. The interdependent economic systems are declining with time. 
32 A A Thermodynamic Formulation of Economics

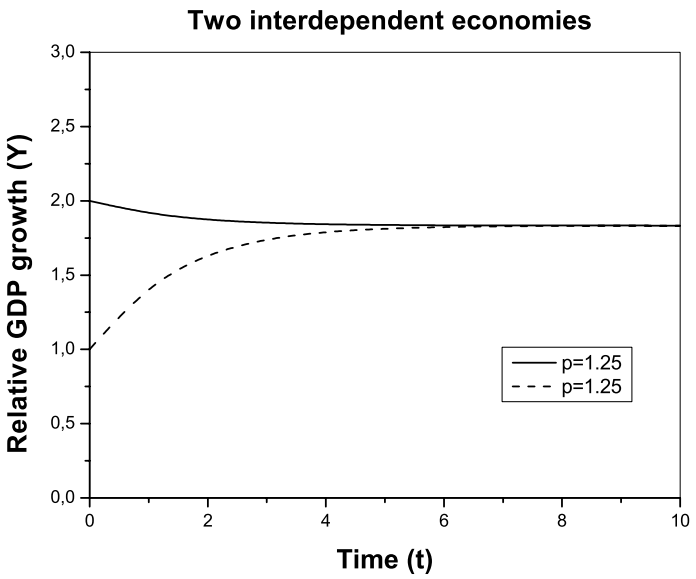

Fig. 1.21 The development of the standard of living of two interdependent economic systems starting at $Y_{1}=1$ and $Y_{2}=2$. At very high values of profit for the poor side, $p>1$ both economies will converge below $Y_{2}=2$.

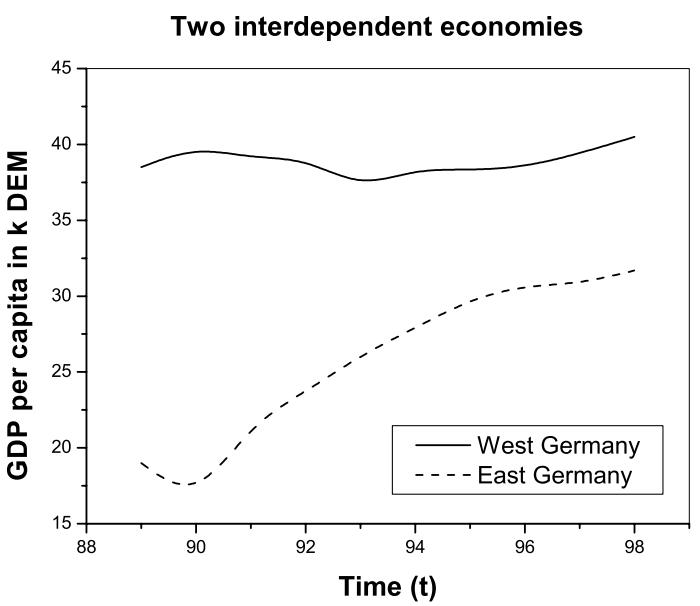

Fig. 1.22 Real standard of living in West and Germany between 1989 and 1998 due to productivity and capital transfer. In 1998 East Germany reached about $80 \%$ of the living standard in West Germany. 


\section{References}

1 ARUKA, Y. (Ed.), Evolutionary Controversies in Economics, Springer, Tokyo, 2001

2 CIA World Factbook, USA, 2004

3 DrĂgulescu, A. A., YAKovenko, V. M. Eur. Phys. J. B 20 (2001)

4 Foley, D. K., Journal of Economic Theory 62, No. 2, (1994)

5 Fowler, R., Guggenheim, E. A., Statistical Thermodynamics, Cambridge University Press, 1960

6 Kaplan, W., Advanced Calculus, AddisonWesley, 2003

7 Georgescu-Roegen, N., The Entropy Law and the Economic Process, Cambridge, Mass. Harvard Univ. Press, 1974

8 LEVY, M., LeVY, H., SOlOMON, S., Microscopic Simulation of Financial Markets, Academic Press, New York, 2000

9 MiMkes, J., J. Thermal Analysis 60 (2000), p. 1055-1069

10 Mimkes, J., J. Thermal Analysis 43 (1995), p. 521-537

11 Mimkes, J., Willis, G., in Econophysics of Wealth Distributions, CHATTERJEE, A.
YARLAGADDA, S., CHAKRABARTI, B K., (Eds.), Springer-Verlag Italia, Milan, 2005

12 Mimkes, J., ARUKA, Y., in Econophysics of Wealth Distributions, CHATTERJEE, A., YARLAGADDA, S., CHAKRABARTI, B. K., (Ed.), Springer-Verlag Italia, Milan, 2005

13 Silva, A. C, Yakovenko, V. M., Europhysics Letters 69 (2005), p. 304-310

14 Solomon, S, Richmond, P., in Economics with Heterogeneous Interacting Agents, Kirman, A., ZimMERMANN, J.-B. (Ed.), Springer-Verlag, Heidelberg 2001

15 Stanley, H. E., Amaral, L. A. N., CaNNING, D., GOPIKRISHNAN, P., LEEA Y. AND LiUA, Y., Physica A 269 (1999), p. 156169

16 Weidlich, W., Sociodynamics, Amsterdam: Harwood Acad. Publ., 2000

17 WeIDLICH, W., The use of statistical models in sociology, Collective Phenomena 1 (1972), p. 51

18 Willis, G., Mimkes, J., Condmat/0406694. 
